\title{
COMPARISON BETWEEN VOLUME CONTROLLED VENTILATION AND PRESSURE CONTROLLED VENTILATION AS REGARDS EFFECTS ON RESPIRATORY PARAMETERS AND NEED OF POSTOPERATIVE VENTILATION IN LAPAROSCOPIC BARIATRIC SURGERIES
}

\author{
Amir Ibrahim Mohamed Salah, Adel Mikhail Fahmy Shonoda, \\ Khaled Mostafa Khalaf \& Ramy Hasan Naser Ibrahim Zoair*
}

\begin{abstract}
Anesthesiology Department, Faculty of Medicine, Ain Shams University, Cairo, Egypt

Corresponding Author: Ramy Hasan Naser Zoair Mobile: .: (+2) 01003552849. E-mail: dr.ramyhasan@gmail.com Received: $14 / 7 / 2020$ Accepted: 5/8/2020
\end{abstract}

Online ISSN: $\mathbf{2 7 3 5 - 3 5 4 0}$

\begin{abstract}
:
Background: Managing ventilation and oxygenation during laparoscopic bariatric procedures in morbidly obese patients represents many challenges.
\end{abstract}

Aim of the Work: To compare the effect of these modes of ventilation on respiratory parameters in obese patients undergoing laparoscopic bariatric surgeries and whether this influences the need of postoperative ventilation or not

Patients and Methods: After approval of ethical committee of faculty of Medicine Ain Shams University and obtaining an informed consent from every patient, this randomized controlled clinical trial study was conducted at Ain Shams University Hospitals operating theatre department on 40 obese adult patients of ASA physical status I - II, admitted to Ain Shams university hospital, scheduled for elective laparoscopic bariatric surgery. General anesthesia with endotracheal intubation and controlled ventilation was conducted in all patients. Patients were divided randomly into two equal groups: Group A; received volume controlled ventilation and Group $B$; received pressure controlled ventilation.

Results: The study found no significant difference between the two groups as regards $\mathrm{PaO} 2$ and $\mathrm{PaO} 2$ :FiO2 preoperatively, after pneumoperitonium, at the end of surgery and postoperatively. As regards $\mathrm{PaCO} 2$ there was no statistically significant difference between the two groups in the preoperative measurement while there was statistically highly significant difference between the two groups after pneumoperitonium, at the end of surgery and postoperatively with lower PaCO2 in group (B) that received PCV than group (A) that received $V C V$. There was statistically highly significant difference between the two groups as regards dynamic compliance after intubation, after pneumoperitonium and at the end of the surgery with higher dynamic compliance in group (B) that received PCV. The results showed no statistically significant difference between the two studied groups regarding the need of post-operative ventilation.

Conclusion: No significant difference between pressure controlled ventilation and volume controlled ventilation regarding oxygenation and the need of postoperative ventilation but PaCo2 levels are lower and dynamic compliance is higher with pressure controlled ventilation. 
Keywords: Volume controlled ventilation, Pressure controlled ventilation, Laparoscopic bariatric surgeries, Obesity

\section{INTRODUCTION:}

Obesity is a complex disease having multifactorial etiology. It is caused by abnormal or excessive accumulation of adipose tissue in the body. Obesity became an epidemic which had worsened for the last 50 years. It is considered to be the second most common cause of preventable death after smoking. It is associated with many medical conditions and can lead to serious complications. A $5 \%$ to $10 \%$ weight loss can improve health, quality of life, and economic burden of individuals and countries ${ }^{(1)}$.

Volume controlled ventilation mode (VCV) is commonly used during general anesthesia. The minute ventilation is fixed while pulmonary resistance and compliance influence the airway pressure. A constant flow is used in volume controlled ventilation (VCV) to deliver tidal volume but this may result in higher airway pressures while in Pressure controlled ventilation (PCV) a decelerating flow is used that reaches the highest value at the beginning of inspiration with a preset pressure limitation to achieve and maintain the set inspiratory pressure quickly followed by decelerating flow ${ }^{(2)}$.

In Laparoscopic surgeries patients may receive low tidal volumes during pneumoperitoneum due to increased pressure. Pneumoperitoneum decreases chest wall and lung compliance and decreases functional residual capacity and these effects lead to decreased alveolar ventilation ${ }^{(3)}$.

It is important to optimize intraoperative mechanical ventilation especially in obese patients to decrease the incidence of postoperative pulmonary complications and to improve the outcome ${ }^{(4)}$.

Obesity causes pathophysiological changes that make obese patients prone to peri-operative complications especially pulmonary complications that are the main reason for peri-operative morbidity and mortality after general anesthesia. Pneumonia, atelectasis, carbon dioxide retention may extend to the postoperative period causing delayed discharge from post anesthesia care unit, increased need for respiratory physiotherapy or non- invasive ventilation and increased probability of admission to intensive care unit. Preventing these complications would decrease hospital stay and improve the quality of medical care (5).

In obese patients decreased pulmonary compliance results in reduced vital capacity, functional residual capacity (FRC) and total lung capacity. Decreased FRC leads to lung volumes below the closing capacity during normal tidal ventilation causing closure of small airway, ventilation-perfusion mismatch and arterial hypoxemia. Anesthesia worsens this as up to $50 \%$ decrease in FRC happens in obese patients under anesthesia in comparison with $20 \%$ among the non-obese ${ }^{(6)}$.

\section{AIM OF THE WORK:}

This study aims to compare the effect of volume controlled ventilation and pressure controlled ventilation on respiratory parameters and the need of postoperative ventilation for morbidly obese patients undergoing laparoscopic bariatric surgery in order to decrease complications.

\section{PATIENTS AND METHODS:}

After approval of ethical committee of faculty of Medicine Ain Shams University and obtaining an informed consent from every patient, this randomized controlled clinical trial study was conducted at Ain Shams University 
Hospitals operating theatre department on 40 obese adult patients of ASA physical status I II, admitted to Ain Shams university hospital, scheduled for elective laparoscopic bariatric surgery. The patients were subdivided into 2 groups A and B with (20) patients for each group.

\section{Inclusion criteria:}

1- Patients of both sexes with BMI ranging from $35-45 \mathrm{~kg} / \mathrm{m} 2$

2- Aging between 25-45 years old

3- Patients of ASA physical status I - II.

4- Scheduled for elective laparoscopic bariatric surgeries

\section{Exclusion criteria:}

1- Patients with cardiac diseases such as ischemic heart diseases and valvular heart diseases.

2- Patients with pulmonary diseases such as chronic obstructive lung disease, bronchial asthma and pulmonary fibrosis.

3- Any complications occurred that necessitated laparotomy Methodology:

\section{Preoperative assessment:}

Patients were visited preoperatively to take history, examine the patients, review investigations and to start a good doctor patient relationship.

\section{Intraoperative management:}

\section{A) Patient preparation:}

Patients included in the study fasted for at least $8 \mathrm{hrs}$ before induction of anesthesia. A peripheral venous access was inserted and secured and a baseline arterial blood sample was drawn for arterial blood gas (ABG) analysis.

Patients were premedicated with metoclopramide $10 \mathrm{mg}$ IV before induction of anesthesia.

\section{B) Monitoring:}

Monitoring was started before induction of anesthesia, monitors applied were:
1) Non-invasive blood pressure monitoring every five minutes with a large cuff suitable for obese patients.

2) 5 leads ECG to monitor heart rate and rhythm continuously.

3) Pulse oximetry to monitor oxygen saturation continuously.

4) Capnography to monitor the end tidal $\mathrm{CO} 2$ and end tidal inhalational anesthestic continuously.

\section{C) Induction of anesthesia:}

After administration of $100 \% \mathrm{O} 2$ by face mask for 3-5 min, patients received intravenous injection of $1.5 \mathrm{mg} / \mathrm{kg}$ propofol, $2 \mu \mathrm{g} / \mathrm{kg}$ fentanyl, $0.5 \mathrm{mg} / \mathrm{kg}$ atracurium to facilitate tracheal intubation.

Anesthesia was maintained using 1.2 MAC isoflurane, $0.5 \mu \mathrm{g} / \mathrm{kg} / \mathrm{hr}$ fentanyl by intravenous infusion and $0.15 \mathrm{mg} / \mathrm{kg}$ atracurium boluses every $30 \mathrm{~min}$.

Patients were randomized with the help of a computer-generated random number list to receive the selected mode of ventilation.

Group (A): The patients received volume controlled ventilation with tidal volume $6 \mathrm{ml} / \mathrm{kg}$, breathing rate 14 breath per minute, I:E ratio 1:2 and PEEP $10 \mathrm{cmH} 2 \mathrm{O}$.

Group (B): The patients received pressure controlled ventilation with target tidal volume $6 \mathrm{ml} / \mathrm{kg}$, breathing rate 14 breath per minute, I:E ratio 1:2 and PEEP 10 cmH2O.

Carbon dioxide was insufflated into the peritoneal cavity and the upper limit of intraabdominal pressure was set at $13 \mathrm{mmHg}$.

Crystalloid solution at a rate of 20 $\mathrm{ml} / \mathrm{kg} / \mathrm{hr}$ was administrated starting immediately before induction of anesthesia until patient positioning, followed by 5 $\mathrm{ml} / \mathrm{kg} / \mathrm{hr}$ until the end of the surgery. Intraoperative hypotension (decrease in MAP > $25 \%$ of base line) was treated with a bolus of normal saline $0.9 \% 25 \mathrm{ml}$ and /or incremental dose of ephedrine $6 \mathrm{mg}$. 


\section{D) Emergence from anesthesia:}

At the end of the surgery, Isoflurane and fentanyl infusion were discontinued, muscle relaxation was reversed by neostigmine 0.05 $\mathrm{mg} / \mathrm{kg}$ and $0.015 \mathrm{mg} / \mathrm{kg}$ atropine sulphate. Tracheal extubation was performed in a semi-setting position after reaching satisfactory criteria for extubation.

The patients were transferred to the ICU in the semi-setting position with supplementation of oxygen by venturi face mask $40 \%$ with good postoperative analgesia.

\section{Measurements:}

I. Arterial blood gas samples were taken pre-operatively, after administration of pneumoperitonium, at the end of surgery ,post operatively to measure partial pressure of oxygen $(\mathrm{PaO} 2)$, to calculate the ratio between $\mathrm{PaO} 2 / \mathrm{FiO} 2$ and to measure partial pressure of Carbon dioxide ( $\mathrm{PaCo} 2)$.

II. Dynamic compliance was calculated after intubation, after pneumoperitonium and at the end of surgery using the equation:

$\mathrm{C}_{\mathrm{dyn}}=\mathrm{V}_{\mathrm{T}} /(\mathrm{PIP}-\mathrm{PEEP})$

Where:

$\mathrm{C}_{\mathrm{dyn}}=$ Dynamic compliance

$\mathrm{V}_{\mathrm{T}}=$ Tidal volume

$\mathrm{PIP}=$ Peak inspiratory pressure

Pressure

$\mathrm{PEEP}=$ Positive End Expiratory

III. The need for postoperative ventilation in the first 24 hours of postoperative period was recorded in ICU according to findings of $\mathrm{ABG}$ and spirometry.
Mechanical ventilation was done if $\mathrm{PaO} 2<60 \mathrm{mmHg}$ or $\mathrm{PaCO} 2>55$ $\mathrm{mmHg}$ or negative inspiratory pressure less than $20 \mathrm{cmH} 2 \mathrm{O}$.

\section{Statistical Analysis:}

Data were collected, revised, coded and entered to the Statistical Package for Social Science (IBM SPSS) version 23. The distribution of quantitative data was tested by Kolmogorov-Smirnov test of normality. So, the quantitative data were presented as mean, standard deviations and ranges when parametric while qualitative variables were presented as number and percentages.

The comparison between groups regarding qualitative data was done by using Chi-square test.

The comparison between two independent groups with quantitative data and parametric distribution was done by using Independent t-test.

The confidence interval was set to $95 \%$ and the margin of error accepted was set to $5 \%$. So, the p-value was considered significant as the following:

$$
\begin{aligned}
& \text { P-value > 0.05: Non significant (NS) } \\
& \text { P-value < 0.05: Significant (S) } \\
& \text { P-value < 0.01: Highly significant (HS) }
\end{aligned}
$$

\section{RESULTS:}

The results showed no statistically significant difference between the two groups as regards age, sex, body weight, height and Body Mass Index (BMI) as shown in (Table 1) 


\section{Comparison Between Volume Controlled Ventilation And Pressure Controlled Ventilation As...}

Table (1): Comparison between the two groups as regards age, sex, body weight, height and Body Mass Index (BMI)

\begin{tabular}{|c|c|c|c|c|c|c|}
\hline & Group (A) & Group (B) & \multirow{2}{*}{$\begin{array}{c}\text { Test } \\
\text { value }\end{array}$} & \multirow{2}{*}{$\begin{array}{c}\text { P- } \\
\text { value }\end{array}$} & \multirow[t]{2}{*}{ Sig. } \\
\hline & & No. $=20$ & No. $=20$ & & & \\
\hline \multirow[t]{2}{*}{ Age (years) } & Mean \pm SD & $35.55 \pm 4.77$ & $35.35 \pm 3.01$ & \multirow[t]{2}{*}{$0.158 \bullet$} & \multirow[t]{2}{*}{0.875} & \multirow[t]{2}{*}{ NS } \\
\hline & Range & $27-45$ & $29-40$ & & & \\
\hline \multirow[t]{2}{*}{ Sex } & Female & $10(50.0 \%)$ & $11(55.0 \%)$ & \multirow[t]{2}{*}{$0.100^{*}$} & \multirow[t]{2}{*}{0.752} & \multirow[t]{2}{*}{ NS } \\
\hline & Male & $10(50.0 \%)$ & $9(45.0 \%)$ & & & \\
\hline \multirow{2}{*}{$\begin{array}{l}\text { Body weight } \\
(\mathrm{Kg})\end{array}$} & Mean \pm SD & $125.50 \pm 6.00$ & $125.55 \pm 3.14$ & \multirow[t]{2}{*}{$-0.033^{\bullet}$} & \multirow[t]{2}{*}{0.974} & \multirow[t]{2}{*}{ NS } \\
\hline & Range & $115-136$ & $119-130$ & & & \\
\hline \multirow[t]{2}{*}{ Height (m) } & Mean \pm SD & $1.73 \pm 0.05$ & $1.73 \pm 0.05$ & \multirow[t]{2}{*}{$-0.064 \bullet$} & \multirow[t]{2}{*}{0.950} & \multirow[t]{2}{*}{ NS } \\
\hline & Range & $1.66-1.81$ & $1.67-1.8$ & & & \\
\hline \multirow{2}{*}{$\begin{array}{l}\text { Body Mass Index (BMI) } \\
(\mathrm{Kg} / \mathrm{m} 2)\end{array}$} & Mean \pm SD & $42.02 \pm 1.42$ & $42.05 \pm 2.20$ & \multirow[t]{2}{*}{$-0.049 \bullet$} & \multirow[t]{2}{*}{0.961} & \multirow[t]{2}{*}{ NS } \\
\hline & Range & $40.03-44.64$ & $37.14-45.17$ & & & \\
\hline
\end{tabular}

Group (A): Patients received VCV, Group (B):Patients received PCV

$P$-value >0.05: Non significant (NS); P-value <0.05: Significant (S); P-value <0.01: highly significant $(H S) \quad *$ :Chi-square test; $\bullet:$ Independent $t$-test

\section{PaO2, PaO2:FiO2, PaCO2:}

The results showed no statistically significant difference between the two groups as regards $\mathrm{PaO} 2$ and $\mathrm{PaO} 2 / \mathrm{FiO} 2$ in all the times of measurement. Regarding $\mathrm{PaCO} 2$ there was no statistically significant difference between the two groups in the Table (2): Comparison between the two studied groups regarding $(\mathrm{PaO} 2, \mathrm{PaO} 2 / \mathrm{FiO} 2$ and $\mathrm{PaCo} 2)$ preoperative, after pneumoperitonium, at the end of surgery and postoperative

\begin{tabular}{|c|c|c|c|c|c|c|}
\hline \multirow{2}{*}{\multicolumn{2}{|c|}{$\mathrm{ABG}$}} & Group (A) & Group (B) & \multirow{2}{*}{$\begin{array}{c}\text { Test } \\
\text { value• }\end{array}$} & \multirow[t]{2}{*}{ P-value } & \multirow[t]{2}{*}{ Sig. } \\
\hline & & No. $=20$ & No. $=20$ & & & \\
\hline \multicolumn{7}{|l|}{ Preoperative } \\
\hline \multirow{2}{*}{$\begin{array}{c}\mathrm{PaO} 2 \\
(\mathrm{mmHg})\end{array}$} & Mean \pm SD & $75.55 \pm 3.73$ & $75.70 \pm 3.26$ & \multirow[t]{2}{*}{-0.135} & \multirow[t]{2}{*}{0.893} & \multirow[t]{2}{*}{ NS } \\
\hline & Range & $69-82$ & $70-82$ & & & \\
\hline \multirow{2}{*}{$\begin{array}{l}\mathrm{PaO} 2: \\
\mathrm{FiO} 2\end{array}$} & Mean \pm SD & $359.27 \pm 17.47$ & $360.48 \pm 15.53$ & \multirow[t]{2}{*}{-0.230} & \multirow[t]{2}{*}{0.819} & \multirow[t]{2}{*}{ NS } \\
\hline & Range & $328.57-390.48$ & $333.33-390.48$ & & & \\
\hline \multirow{2}{*}{$\begin{array}{c}\mathrm{PaCo} 2 \\
(\mathrm{mmHg})\end{array}$} & Mean \pm SD & $39.45 \pm 1.39$ & $39.55 \pm 2.06$ & \multirow[t]{2}{*}{-0.180} & \multirow[t]{2}{*}{0.858} & \multirow[t]{2}{*}{ NS } \\
\hline & Range & $37-42$ & $36-43$ & & & \\
\hline \multicolumn{7}{|c|}{ After Pneumoperitonium } \\
\hline \multirow{2}{*}{$\begin{array}{c}\mathrm{PaO} 2 \\
(\mathrm{mmHg})\end{array}$} & Mean \pm SD & $185.55 \pm 7.09$ & $186.00 \pm 2.68$ & \multirow[t]{2}{*}{-0.266} & \multirow[t]{2}{*}{0.792} & \multirow[t]{2}{*}{ NS } \\
\hline & Range & $168-199$ & $180-190$ & & & \\
\hline \multirow{2}{*}{$\begin{array}{l}\mathrm{PaO} 2: \\
\mathrm{FiO} 2\end{array}$} & Mean \pm SD & $309.25 \pm 11.82$ & $310.00 \pm 4.46$ & \multirow[t]{2}{*}{-0.265} & \multirow[t]{2}{*}{0.792} & \multirow[t]{2}{*}{ NS } \\
\hline & Range & $280-331.67$ & $300-316.67$ & & & \\
\hline \multirow{2}{*}{$\begin{array}{c}\mathrm{PaCo} 2 \\
(\mathrm{mmHg})\end{array}$} & Mean \pm SD & $41.55 \pm 1.23$ & $37.6 \pm 1.73$ & \multirow[t]{2}{*}{8.322} & \multirow[t]{2}{*}{0.000} & \multirow[t]{2}{*}{ HS } \\
\hline & Range & $39-43$ & $36-40$ & & & \\
\hline \multicolumn{7}{|c|}{ At the end of surgery } \\
\hline \multirow{2}{*}{$\begin{array}{c}\mathrm{PaO} 2 \\
(\mathrm{mmHg})\end{array}$} & Mean \pm SD & $182.20 \pm 9.32$ & $182.30 \pm 3.23$ & \multirow[t]{2}{*}{-0.045} & \multirow[t]{2}{*}{0.964} & \multirow[t]{2}{*}{ NS } \\
\hline & Range & $155-195$ & $175-188$ & & & \\
\hline $\mathrm{PaO} 2: \mathrm{FiO} 2$ & Mean \pm SD & $305.67 \pm 15.13$ & $303.83 \pm 5.38$ & 0.511 & 0.612 & NS \\
\hline & Range & $258.33-325$ & $291.67-313.33$ & & & \\
\hline
\end{tabular}

preoperative measurement while there was statistically highly significant difference between the two groups after pneumoperitonium, at the end of surgery and postoperatively with lower $\mathrm{PaCO} 2$ in group (B) that received PCV than group (A) that received VCV as shown in (Table 2) 
Amir Ibrahim Mohamed Salah, et al.,

\begin{tabular}{|c|c|c|c|c|c|c|}
\hline \multirow{2}{*}{$\begin{array}{c}\mathrm{PaCo} 2 \\
(\mathrm{mmHg})\end{array}$} & Mean \pm SD & $42.55 \pm 1.15$ & $38.45 \pm 1.73$ & \multirow[t]{2}{*}{8.826} & \multirow[t]{2}{*}{0.000} & \multirow[t]{2}{*}{ HS } \\
\hline & Range & $40-44$ & $36-41$ & & & \\
\hline \multicolumn{7}{|l|}{ Postoperative } \\
\hline \multirow{2}{*}{$\begin{array}{c}\mathrm{PaO} 2 \\
(\mathrm{mmHg})\end{array}$} & Mean \pm SD & $115.55 \pm 6.82$ & $115.60 \pm 2.76$ & \multirow[t]{2}{*}{-0.030} & \multirow[t]{2}{*}{0.976} & \multirow[t]{2}{*}{ NS } \\
\hline & Range & $102-124$ & $112-121$ & & & \\
\hline \multirow{2}{*}{$\begin{array}{l}\mathrm{PaO} 2: \\
\text { FiO2 }\end{array}$} & Mean \pm SD & $288.88 \pm 17.04$ & $289.00 \pm 6.90$ & \multirow[t]{2}{*}{-0.030} & \multirow[t]{2}{*}{0.976} & \multirow[t]{2}{*}{ NS } \\
\hline & Range & $255-310$ & $280-302.5$ & & & \\
\hline \multirow{2}{*}{$\begin{array}{c}\mathrm{PaCo} 2 \\
(\mathrm{mmHg})\end{array}$} & Mean \pm SD & $43.40 \pm 1.27$ & $39.5 \pm 1.64$ & \multirow[t]{2}{*}{8.409} & \multirow[t]{2}{*}{0.000} & \multirow[t]{2}{*}{ HS } \\
\hline & Range & $41-45$ & $37-42$ & & & \\
\hline
\end{tabular}

Group (A): Patients received VCV, Group (B): Patients received PCV

P-value >0.05: Non significant (NS); P-value <0.05: Significant (S); P-value< 0.01: highly significant $(H S)$

\section{$\because$ Independent t-test}

\section{Dynamic compliance:}

The results showed that there was statistically highly significant difference between the two groups as regards dynamic compliance after intubation, after pneumoperitonium and at the end of the surgery with higher dynamic compliance in group (B) that received PCV as shown in (Table 3)

Table (3): Comparison between the two groups as regards dynamic compliance after intubation, after pneumoperitonium and at the end of surgery.

\begin{tabular}{|c|c|c|c|c|c|c|}
\hline \multicolumn{2}{|c|}{ Dynamic compliance (ml/cmH2o) } & Group (A) & Group (B) & $\begin{array}{c}\text { Test } \\
\text { value }\end{array}$ & P-value & Sig. \\
\cline { 3 - 5 } \multicolumn{2}{|c|}{} & No. $=20$ & No. $=20$ & & \\
\hline \multirow{2}{*}{ After intubation } & Mean \pm SD & $22.62 \pm 3.10$ & $28.23 \pm 2.95$ & -5.863 & 0.000 & HS \\
\cline { 2 - 5 } & Range & $17.2-28.06$ & $23.61-35$ & & & \\
\hline \multirow{2}{*}{ After } & Mean \pm SD & $17.84 \pm 1.96$ & $23.02 \pm 2.13$ & -8.003 & 0.000 & HS \\
\cline { 2 - 4 } At the end of surgery & Range & $15.18-21.09$ & $19.55-26.39$ & & & \\
\hline & Mean \pm SD & $21.34 \pm 2.99$ & $26.59 \pm 2.57$ & -5.955 & 0.000 & HS \\
\cline { 2 - 4 } & Range & $15.93-26.58$ & $23.75-31.67$ & & & \\
\hline
\end{tabular}

Group (A): Patients received VCV, Group (B): Patients received PCV.

P-value >0.05: Non significant (NS); P-value <0.05: Significant (S); P-value< 0.01: highly significant $(H S) \cdot:$ Independent $t$-test

The need of postoperative ventilation:

The results showed no statistically significant difference between the two studied groups regarding the need of postoperative ventilation as shown in (Table 4)

Table (4): Comparison between the two groups as regards the need of post-operative ventilation

\begin{tabular}{|c|c|c|c|c|c|c|c|}
\hline \multirow{2}{*}{$\begin{array}{c}\text { Need of post- } \\
\text { operative } \\
\text { ventilation }\end{array}$} & \multicolumn{2}{|c|}{ Group (A) } & \multicolumn{2}{|c|}{ Group (B) } & Test value* & P-value & Sig. \\
\cline { 2 - 5 } & No. & $\%$ & No. & $\%$ & & & \\
\hline No & 18 & $90.0 \%$ & 20 & $100.0 \%$ & 2.105 & 0.147 & NS \\
\hline Yes & 2 & $10.0 \%$ & 0 & $0.0 \%$ & & & \\
\hline
\end{tabular}

Group (A): Patients received VCV, Group (B): Patients received PCV

$P$-value >0.05: Non significant (NS); P-value <0.05: Significant (S); P-value<0.01: highly significant $(H S) *$ :Chi-square test 


\section{DISCUSSION:}

The current study was done to compare between volume controlled ventilation and pressure controlled ventilation in obese patients undergoing laparoscopic bariatric surgeries as regards effects on respiratory parameters such as $\mathrm{PaO} 2, \mathrm{PaO} 2: \mathrm{FiO} 2$, $\mathrm{PaCO} 2$ and to compare the effect on dynamic compliance of the respiratory system and to compare the effect on the need of postoperative ventilation.

The study showed no significant difference between the two groups regarding oxygenation but there was a significant lower $\mathrm{PaCo} 2$ with pressure controlled ventilation after pneumoperitonium, at the end of surgery and postoperatively in spite of no significant difference between the two groups preoperatively. It also showed higher dynamic compliance with pressure controlled ventilation after intubation, after pneumoperitonium and at the end of surgery. It also showed no statistically significant difference as regards the need of postoperative ventilation between the two groups.

Any increase in abdominal pressure may decrease functional residual capacity because the diaphragm is mechanically coupled to the abdominal wall. During laparoscopy, the increased abdominal pressure distends the abdominal wall and shifts the diaphragm cranially ${ }^{(7)}$.

Moreover, pneumoperitoneum causes $68 \%$ higher inspiratory resistance and $30 \%$ lower compliance in anesthetized supine obese patients compared with patients of normal weight. During laparoscopy, decreased FRC, pulmonary shunting and ventilation-perfusion mismatch contribute to the decreased arterial oxygenation, in addition to atelectasis that is exaggerated in the obese patients ${ }^{(8)}$.
Many studies were performed to determine the optimal settings in ventilation of such patients. The primary goal of mechanical ventilation is to maintain adequate gas exchange with minimum lung injury ${ }^{(9)}$.

So this study was performed to compare between volume controlled ventilation and pressure controlled ventilation to determine the optimal ventilatory mode in these patients.

Regarding oxygenation, the current study showed no significant difference between the two studied groups in $\mathrm{PaO} 2$ and $\mathrm{PaO} 2 / \mathrm{FiO} 2$ preoperatively, after pneumoperitonium, at the end of surgery and postoperativly.

In support with the current study, a study done by Jaju and colleagues ${ }^{(10)}$ on sixty patients undergoing robot-assisted pelvic surgeries to compare between volume controlled ventilation and pressure controlled ventilation showed no significant difference in oxygenation between the two groups.

The current study is consistent with the meta-analysis done by Aldenkortt and his colleagues $^{(11)}$ including four trials with one hundred patients to compare between volume controlled ventilation and pressure controlled ventilation and showed no significant difference between the two groups as regards oxygenation.

The current study was consistent with a study done by De Baerdemaeker and colleagues $^{(12)}$ on 24 patients comparing between volume controlled ventilation and pressure controlled ventilation in laparoscopic gastric banding in morbid obese patients and reported no significant difference in oxygenation between the two groups.

Consistently, Hans and colleagues ${ }^{(13)}$ found that there was no significant difference in $\mathrm{PaO} 2$ between volume 
controlled ventilation and pressure controlled ventilation in forty morbidly obese patients undergoing gastric bypass surgery.

Also our study is consistent with a study done by Balick-Weber and colleagues ${ }^{(14)}$ on 21 patients undergoing laparoscopic urological procedures which noted no significant difference in oxygenation after switching the ventilation mode from volume controlled ventilation to pressure controlled ventilation.

On the other hand, Movassagi and colleagues $^{(15)}$ performed a study on seventy obese patients undergoing laparoscopic cholecystectomy comparing between volume controlled ventilation and pressure controlled ventilation and reported no significant difference between the two groups regarding $\mathrm{PaO}_{2}$ except 35 minutes and 55 minutes after pneumoperitoneum. In the mentioned times, patients in pressure controlled ventilation group had significantly higher $\mathrm{PO}_{2}$ levels compared to volume controlled ventilation group. This may be due to the different method of the study which used different settings of ventilation which may affect the results. The study used higher tidal volume $(8 \mathrm{ml} / \mathrm{kg})$ and lower PEEP ( $5 \mathrm{cmH} 2 \mathrm{o})$ than our study.

Inconsistently with the current study, a study done by Sen and colleagues ${ }^{(16)}$ on forty patients undergoing laparoscopic cholecystectomy reported statistically significant difference between volume controlled ventilation and pressure controlled ventilation groups as regards post-operative $\mathrm{PaO} 2$ in favor of pressure controlled ventilation but reported no significant difference between the two groups as regards intraoperative $\mathrm{PaO} 2$. These results may be affected by the different type of patients in this study (nonobese patients with BMI $<30 \mathrm{~kg} / \mathrm{m} 2$ ) and may be also due to different settings of ventilation used in this study with higher tidal volume $(8 \mathrm{ml} / \mathrm{kg})$ and lower PEEP (5 cmH2o) than in our study.

Our study was also inconsistent with a study done by Gupta and colleagues ${ }^{(17)}$ on one hundred and two obese patients undergoing laparoscopic cholecystectomy that reported statistically significant increase in $\mathrm{PaO} 2$ in pressure controlled ventilation group than in volume controlled ventilation group 35 minutes after pneumoperitoneum. This may be because this study targeted obese patients with BMI $30-40 \mathrm{~kg} / \mathrm{m} 2$ compared with our targeted group of obese patients with BMI $35-45 \mathrm{~kg} / \mathrm{m} 2$. The different method of ventilation also may affect the results because this study used volume controlled ventilation in all the patients in the beginning of the operation and then shifted one group of patients to pressure controlled ventilation after pneumoperitonium by fifteen minutes.

Our study is also inconsistent with a study carried by Cadi and colleagues ${ }^{(18)}$ on thirty six obese patients with BMI more than $35 \mathrm{~kg} / \mathrm{m} 2$ that reported significant differences in arterial blood oxygenation $\left(\mathrm{Pa}_{02}\right.$ and $\left.\mathrm{Sa}_{\mathrm{o} 2}\right)$ in favor of the pressure controlled ventilation mode during laparoscopic obesity surgery. This may be explained by the different ventilatory settings used in this study with lower PEEP (5 $\mathrm{cmH} 2 \mathrm{o})$ and higher tidal volume (8 $\mathrm{ml} / \mathrm{kg}$ ) than in our study.

Regarding $\mathrm{PaCo} 2$, the current study showed statistically significant lower $\mathrm{PaCo} 2$ in group (B) that received pressure controlled ventilation than in group (A) that received volume controlled ventilation after pneumoperitonium, at the end of surgery and postoperatively in spite of no significant difference between the two groups preoperatively.

This was consistent with the study carried by Jaju and colleagues ${ }^{(10)}$ that reported also lower $\mathrm{PaCo} 2$ in pressure controlled ventilation group than volume 
controlled ventilation group in robot-assisted pelvic surgeries.

Consistently with the current study, Cadi and colleagues ${ }^{(18)}$ also concluded lower $\mathrm{PaCo} 2$ in pressure controlled ventilation group than in volume controlled ventilation group laparoscopic obesity surgeries.

On the other hand, Sen and colleagues $^{(16)}$ also reported lower $\mathrm{PaCo} 2$ with pressure controlled ventilation group in laparoscopic cholecystectomy during pneumoperitonium but reported no statistically significant difference between the two groups postoperatively. This result may be affected by the different type of patients in this study (non-obese patients with BMI $<30 \mathrm{~kg} / \mathrm{m} 2$ ) and may be also due to different settings of ventilation used in this study with higher tidal volume $(8 \mathrm{ml} / \mathrm{kg})$ and lower PEEP $(5 \mathrm{cmH} 2 \mathrm{o})$ than in our study.

In contrast to our study, Movassagi and colleagues $^{(15)}$ and Gupta and colleagues ${ }^{(17)}$ reported no statistically significant difference between volume controlled ventilation group and pressure controlled ventilation group regarding $\mathrm{PaCO} 2$ in obese patients undergoing laparoscopic cholecystectomy. This may be due to the different methodology because in these studies all patients received volume controlled ventilation in the beginning of the procedure then the patients were subdivided into two groups after pneumoperitonium with one group shifted to pressure controlled ventilation.

Also Hans and colleagues ${ }^{(13)}$ reported that there is no statistically significant difference between volume controlled ventilation and pressure controlled ventilation as regards $\mathrm{PaCo} 2$ in obese patients undergoing abdominal surgeries. This may be due to the different type of surgery with no pneumoperitonium and due to the different methodology of this study in which all the patients received volume controlled ventilation for the $1^{\text {st }}$ hour in surgery then the patients were subdivided into two groups with one of them to be changed to pressure controlled ventilation.

Inconsistently with our study De Baerdemaeker and colleagues ${ }^{(12)}$ reported lower $\mathrm{PaCo} 2$ with volume controlled ventilation group than pressure controlled ventilation in obese patients undergoing laparoscopic gastric banding. This may be due to higher tidal volumes used in this study $(10 \mathrm{ml} / \mathrm{kg})$.

Our study is also inconsistent with the study carried by Balick-Weber and colleagues $^{(14)}$ that reported no significant difference in $\mathrm{PaCo} 2$ after switching the mode of ventilation from volume controlled ventilation to pressure controlled ventilation. This may be due to the different methodology of this study with one group of patients and using both modes of ventilation subsequently in the same operation.

Regarding dynamic compliance, this study showed statistically highly significant difference between the two groups with higher dynamic compliance in group (B) that received pressure controlled ventilation.

In support to our study, Jaju and colleagues $^{(10)}$ reported higher dynamic compliance in pressure controlled ventilation group than in volume controlled ventilation group in robot assisted pelvic surgeries.

Our study is also consistent with a study performed by Liao and colleagues ${ }^{(19)}$ on fifty two women undergoing laparoscopic gynecological surgeries and reported higher dynamic compliance in the pressure controlled ventilation group than in the volume controlled ventilation group.

Our study is consistent with the metaanalysis made be Wang and colleagues ${ }^{(20)}$ that included 428 patients undergoing laparoscopic surgeries and concluded higher dynamic compliance in the pressure controlled ventilation group than in the volume 
controlled ventilation group. Subgroup analysis for morbid obese patients showed the same result.

This was also consistent with a study carried by Choi and colleagues ${ }^{(21)}$ on thirty four patients undergoing robot-assisted laparoscopic radical prostatectomy and reported higher dynamic compliance in pressure controlled ventilation group than in volume controlled ventilation group.

Consistently with the current study, Tyagi and colleagues ${ }^{(22)}$ in their study on forty two patients undergoing laparoscopic cholecystectomy concluded higher dynamic compliance in pressure controlled ventilation group than in volume controlled ventilation group.

Also Ogurlo and colleagues ${ }^{(23)}$ in their study on sixty women undergoing laparoscopic gynecological surgeries reported significantly higher dynamic compliance in pressure controlled ventilation group than in volume controlled ventilation group after pneumoperitonium.

This was also consistent with BalickWeber and colleagues ${ }^{(14)}$ who reported higher dynamic compliance with pressure controlled ventilation than with volume controlled ventilation in laparoscopic urological procedures.

Inconsistently, Sen and colleagues ${ }^{(16)}$ reported higher dynamic compliance after intubation in patients that received pressure controlled ventilation than those patients who received volume controlled ventilation in laparoscopic cholecystectomy but reported also that there was no statistically significant difference between the two groups as regards dynamic compliance after pneumoperitonium. This may be due to different type of patients with lower BMI lacking the negative effect of obesity on respiratory mechanics.

This study is also inconsistent with the results of the study carried by Cadi and colleagues $^{(18)}$ that showed no significant difference between volume controlled ventilation and pressure controlled ventilation groups as regards dynamic compliance in laparoscopic obesity surgeries. This may be explained by the different ventilatory settings used in this study with lower PEEP (5 cmH2o) and higher tidal volume $(8 \mathrm{ml} / \mathrm{kg})$ than in our study.

Regarding the need of postoperative ventilation there was no statistically significant difference between the two studied groups. This matches with Liao and colleagues $^{(19)}$ who reported no significant difference between the two groups as regards postoperative recovery up to 24 hours postoperatively.

The current study has many limitations. Patients with BMI more than $45 \mathrm{~kg} / \mathrm{m} 2$ were excluded from our study although it is expected that the effect of obesity on respiratory parameters is greater in those patients. Also the patients in our study didn't have any pulmonary or cardiac diseases which may affect results so our findings may not be applicable to populations with cardiac or pulmonary diseases. Also the study time was limited to 24 hours postoperatively so later complications can not be excluded.

\section{Conclusion:}

In conclusion there is no significant difference between pressure controlled ventilation and volume controlled ventilation regarding oxygenation and the need of postoperative ventilation but $\mathrm{PaCo} 2$ levels are lower and dynamic compliance is higher with pressure controlled ventilation.

\section{REFERENCES:}

1. Akinkuotu AC, Hamilton JK, Birken C, et al. (2019): Evolution and Outcomes of a Canadian Pediatric Bariatric Surgery Program. J. Pediatr. Surg; (5):1049-1053.

2. Şenay H, Sivacı R, Kokulu S, et al. (2016): The effect of pressure-controlled ventilation 
and volume-controlled ventilation in prone position on pulmonary mechanics and inflammatory markers. Inflammation; 39:1469-74

3. Aydin V, Kabukcu HK, et al. (2016): Comparison of pressure and volumecontrolled ventilation in laparoscopic cholecystectomy operations. Clin Respir J; 10 (3):342-9

4. Ball L, Dameri M, Pelosi P. (2015): Best Pract. Res Clin Anaesthesiol; 29(3):285-99

5. Tianzhu T, Lulong B, Feng C. (2014): Effect of protective ventilation on post-operative pulmonary complications in patients undergoing general anesthesia: a metaanalysis of randomized controlled trials. $\mathrm{Br} \mathbf{J}$ Aneasth; volume 4, issue 6

6. Ogunnaike BO and Whitten CW. (2006): In: Anesthesia and obesity, Clinical Anesthesia. 5th ed. Barash PG, Cullen BF, Stoelting RK, editors. Philadelphia: Lippincott Williams and Wilkins; pp. 1040-52.

7. Gilda C, Salvatore G, Savino S, et al. (2013): Effects of Recruitment Maneuver and Positive End-expiratory Pressure on Respiratory Mechanics and Transpulmonary Pressure during Laparoscopic Surgery. Anesthiology; 118: 114-122.

8. Joris JL. (2005): In: Anesthesia for Laparoscopic Surgery, Miller's Anesthesia. $6^{\text {th }}$ Ed. Miller RD, editor. Philadelphia: Elsevier Churchill Livingstone; pp. 2285-306.

9. Koh SO. (2007): Mode of mechanical ventilation: Volume controlled mode. Crit Care Clin; 23: 161-7.

10. Jaju R, Jaju PB, Dubey M, et al. (2017): Comparison of volume controlled ventilation and pressure controlled ventilation in patients undergoing robot-assisted pelvic surgeries: An open-label trial. Indian $\mathbf{J}$ Anaesth; 61(1):17-23

11. Aldenkortt M, Lysakowski C, Elia N, et al. (2012): Ventilation strategies in obese patients undergoing surgery: a quantitative systematic review and meta-analysis. $\mathrm{Br} \mathrm{J}$ Anaesth; 109(4):493-502

12. Baerdemaeker LD, Herten CV, Gillardin JM, Pattyn P, et al. (2008): Comparison of volume-controlled and pressure-controlled ventilation during laparoscopic gastric banding in morbidly obese patients. Obes Surg; 18:680-5.

13. Hans GA, Prégaldien AA, Kaba A, et al. (2008): Pressure-controlled ventilation does not improve gas exchange in morbidly obese patients undergoing abdominal surgery. Obes Surg; 18(1):71-6

14. Balick-Weber CC, Nicolas P, HedrevilleMontout M,et al. (2007): Respiratory and haemodynamic effects of volume-controlled vs pressure-controlled ventilation during laparoscopy: A cross-over study with echocardiographic assessment. Br J Anaesth; 99:429-35

15. Movassagi R, Montazer M, Mahmoodpoor A, et al. (2017): Comparison of pressure vs. volume controlled ventilation on oxygenation parameters of obese patients undergoing laparoscopic cholecystectomy. Pak J Med Sci; 33(5): 1117-1122

16. Sen O, Umutoglu T, Aydin N, et al. (2016): Effects of pressure-controlled and volumecontrolled ventilation on respiratory mechanics and systemic stress response during laparoscopic cholecystectomy. Springerplus; 5:298

17. Gupta SD, Kundu SB, Ghose T, et al. (2012): A comparison between volume-controlled ventilation and pressure-controlled ventilation in providing better oxygenation in obese patients undergoing laparoscopic cholecystectomy. Indian J Anaesth; 56:27682

18. Cadi P, Guenoun T, Journois D, et al. (2008): Pressure-controlled ventilation improves oxygenation during laparoscopic obesity surgery compared with volume-controlled ventilation. Br J Anaesth; 100:709-16.

19. Liao CC, Kau YC, Ting PC, et al. (2016): The Effects of Volume-Controlled and Pressure-Controlled Ventilation on Lung Mechanics, Oxidative Stress, and Recovery in Gynecologic Laparoscopic Surgery. J Minim Invasive Gynecol; 23(3):410-7

20. Wang JP, Wang HB, Liu YJ, et al. (2015): Comparison of pressure-and volumecontrolled ventilation in laparoscopic surgery: a meta-analysis of randomized controlled trial. Clin Invest Med; 38(3):E119-E141 
21. Choi EM, Na S, Choi SH, et al. (2011): Comparison of volume-controlled and pressure-controlled ventilation in steep Trendelenburg position for robot-assisted laparoscopic radical prostatectomy. J Clin Anesth; 23(3):183-188

22. Tyagi A, Kumar R, et al. (2011): A comparison of pressure-controlled and volume-controlled ventilation for laparoscopic cholecystectomy. Anaesthesia; 66:5038

23. Ogurlo M, Kucu“k M, Bilgin F, et al. (2010): Pressure-controlled vs volume-controlled ventilation during laparoscopic gynecologic surgery. Journal of Minimally Invasive Gynecol; 17:295-300.

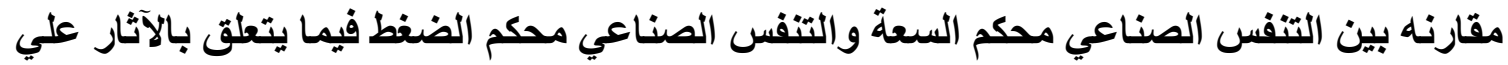

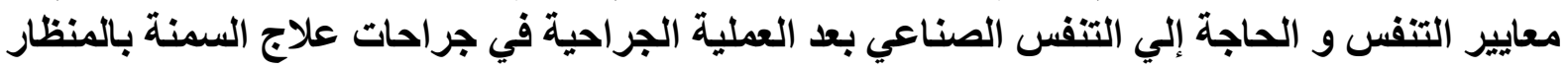

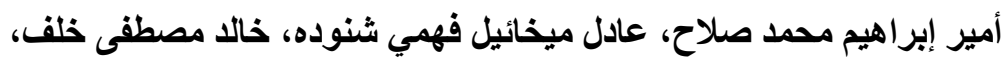

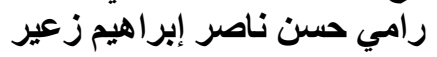

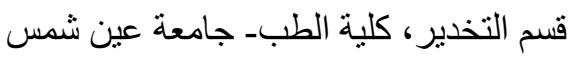

الخلفية: إن التحكم في التنفس الصناعي و زيادة نسبة الأكسجين في الدم أثناء جر احات علاج السمنة بالمنظار في مرضي

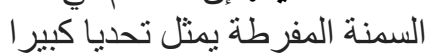

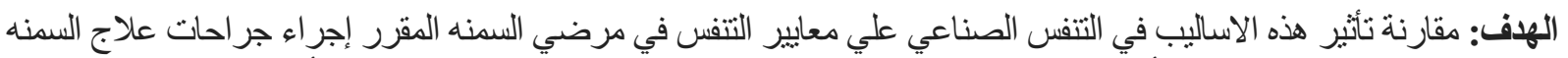

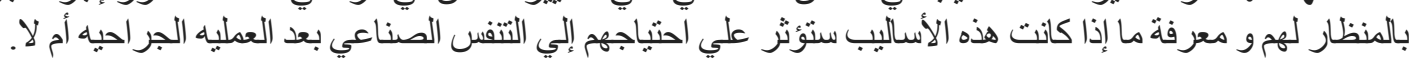

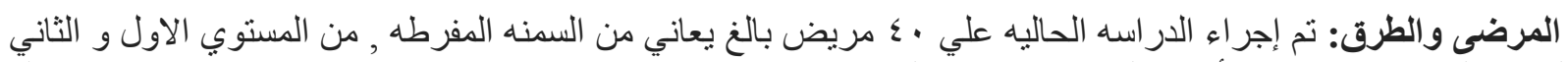

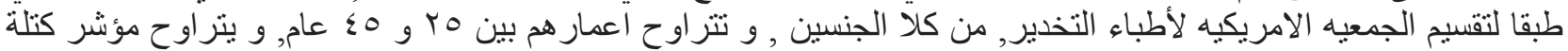

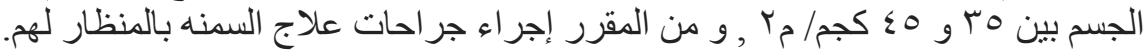

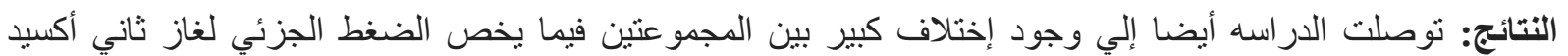

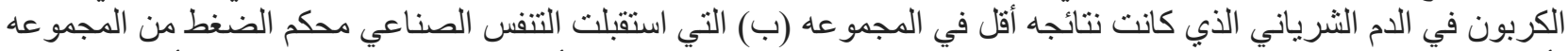

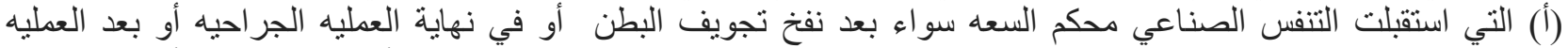

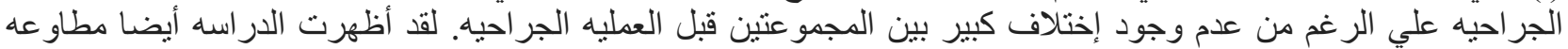

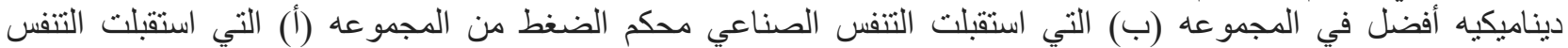
الصناعي محكم السعه سو اء بعد وضع الانبو بها الجنجريه أو بعد نفخ تجويف البطن أو في نهاية العمليه الجراحيه.

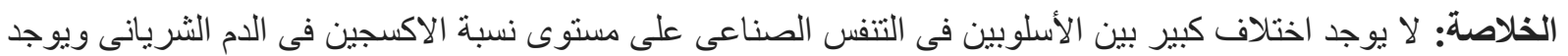

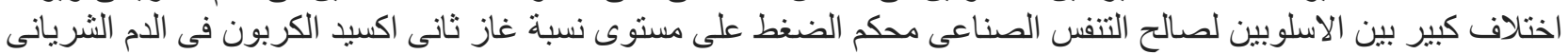

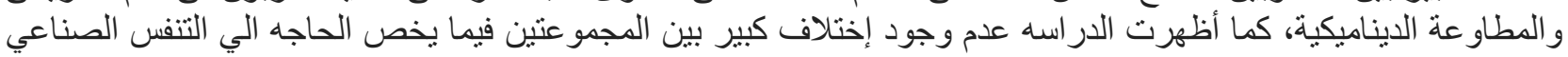

